\title{
Prophylactic mesh to prevent parastomal hernia: further questions need answering
}

\author{
P. A. Blake ${ }^{1}$ G. L. Williams ${ }^{1}$ - B. M. Stephenson ${ }^{1}$
}

Received: 20 February 2017/Accepted: 21 February 2017/Published online: 8 April 2017

(C) Springer International Publishing AG 2017

\section{Dear Sir,}

Sometimes meta-analyses are like buses; a number come along all at once. The final destination may well be similar but the routes can vary. This seems to be the case when the wording of four recently published meta-analyses on the prevention of parastomal herniation (PSH) is scrutinized [1-4]. These looked at 9 studies with 569 patients [1], 10 studies with 649 patients [2], 11 studies [8 randomized controlled trials (RCTs)] with 755 patients [3] and 7 studies with 451 patients [4], respectively. Some reviews included studies described as having a 'high risk of bias' [1, 3], whilst another only included RCTs with a 'low risk' [4].

Despite the overall conclusion(s) that mesh used prophylactically does reduce later parastomal hernia (PSH), its regular use is not presently widespread amongst colorectal surgeons. Interestingly this concept has been around for a long time (over 30 years) and the earliest report on this idea is rarely quoted [5]. Why is mesh-prophylaxis now not routine? Whilst there may be a number of reasons, one might be anxiety about managing patients who later develop a symptomatic PSH. To date there is no published literature on how patients with symptomatic PSH (after prophylaxis) should or could be managed. Is the dissection difficult and if so what morbidity is to be expected? Do the stomas need relocation (with further prophylaxis?) to the contra lateral side, as the rectus muscle must already be weakened and atrophic at the site of the earlier trephine. Is a laparoscopic repair feasible or are the hernial sac and/or contents adherent to the mesh?

B. M. Stephenson

brian.stephenson@wales.nhs.uk

1 Departments of General and Colorectal Surgery, Royal Gwent Hospital, Newport, South Wales, UK
If prophylactic mesh is indeed the answer, it is important for us all to appreciate the potential pitfalls and outcomes of those patients who develop later symptomatic PSHs. Presumably we are not the only practicing coloproctologists who would like to hear how they were managed. Consent issues are also clearly pertinent in today's society but if we knew these answers catching the correct bus in the future would be a lot easier for all concerned.

\section{Compliance with ethical standards}

Conflict of interest The authors declare that they have no conflict of interest.

Ethical approval This article does not contain any studies with human participants or animals by any of the authors.

Informed consent For this type of study formal consent is not required.

\section{References}

1. Patel SV, Zhang L, Chadi SA, Wexner SD (2017) Prophylactic mesh to prevent parastomal hernia: a meta-analysis of randomized controlled studies. Tech Coloproctol 21:5-13

2. Cross AJ, Buchwald PL, Frizelle FA, Eglinton TW (2017) Metaanalysis of prophylactic mesh to prevent parastomal hernia. $\mathrm{Br} \mathrm{J}$ Surg 104:179-186

3. Pianka F, Probst P, Keller AV, Saure D, Grummich K, Büchler MW, Diener MK (2017) Prophylactic mesh placement for the PREvention of paraSTOmal hernias: the PRESTO systematic review and meta-analysis. PLoS ONE 12:e0171548

4. López-Cano M, Brandsma HT, Bury K, Hansson B, Kyle-Leinhase I, Alamino JG, Muysoms F (2017) Prophylactic mesh to prevent parastomal hernia after end colostomy: a meta-analysis and trial sequential analysis. Hernia. doi:10.1007/s10029-016-1563-x

5. Bayer I, Kyzer S, Chaimoff C (1986) A new approach to primary strengthening of colostomy with Marlex mesh to prevent paracolostomy hernia. Surg Gynecol Obstet 163:579-580 